Gut, 1986, 27, 958-963

\title{
Blood flow and perfusion in acute haemorrhagic pancreatitis in the dog
}

\author{
J G N STUdLEY, R T MATHie, M I GibBONS, AND L H BLUMGaRT \\ From the Department of Surgery, Royal Postgraduate Medical School and Hammersmith Hospital, London
}

SUMMARY Experimental evidence suggests that in acute haemorrhagic pancreatitis in the dog the percentage of the cardiac output distributed to the pancreas falls. Histological evidence indicates arteriovenous shunt flow, but this has not been confirmed by flow measurements. It has recently been reported that in experimental preparations in which pancreatic blood flow is measured through the superior pancreaticoduodenal artery after ligation of other (accessory) vessels, perfusion is reduced in distal regions of the gland. There are no data regarding regional perfusion measurements in acute pancreatitis or the effect of ligating accessory vessels. This study therefore evaluates blood flow and regional perfusion in haemorrhagic pancreatitis in various preparations of the canine pancreas. Perfusion was assessed by measuring the clearance of Krypton-85 after injection into the arterial blood supply of the pancreas. Arterial blood flow was measured by the electromagnetic flow technique. The results show that perfusion in different regions of the gland is similar both before and during disease. If accessory vessels are ligated, however, only perfusion in the head of the gland is maintained. No arteriovenous shunt flow was shown. The percentage of the cardiac output being distributed to the gland did not change in any of the experiments; this contradiction to previous reports may arise from the effective control of acid base balance in this study.

Blood flow and perfusion in experimental haemorrhagic pancreatitis in dogs has been extensively studied. Most investigators have demonstrated a fall in flow in acute pancreatitis ${ }^{1-6}$ although some data have been conflicting. ${ }^{7}$. Similarly a fall in the percentage of the cardiac output distributed to the pancreas has been reported during disease,,$^{1} 245$ 8-11 but not all investigators have confirmed this finding. ${ }^{6} 12$

In five of eight studies reporting a fall in flow in relation to the cardiac output, the electromagnetic flow technique was used to measure flow through the superior pancreaticoduodenal artery after ligation of other (accessory) vessels, which include the inferior pancreaticoduodenal artery and branches from the splenic artery. ${ }^{4-11}$ It has been reported that there are poor anastomoses between the superior and inferior pancreaticoduodenal arteries and anomalies in the supply of the body and tail of the gland; consequently it was suggested that when

Address for correspondence: J G N Studley, Department of Surgery, Royal Postgraduate Medical School, and Hammersmith Hospital, London W12 0HS.

Received for publication 12 November 1985. the coeliac axis alone was perfused the perfusion may be reduced in parts of the gland..$^{13}$ In addition, ligation of branches from the splenic artery supplying the pancreas reduces perfusion in the body and tail of the gland. ${ }^{6}$ Perfusion in different regions of the gland in acute pancreatitis has never been assessed and it is unknown what effect ligation of the accessory vessels has on the disease.

Histological evidence indicates that in haemorrhagic pancreatitis there is increased flow through arteriovenous shunts, ${ }^{14}$ but measurements of blood flow have not indicated any significant change in arteriovenous shunt flow. ${ }^{6}$

\section{Methods}

\section{EXPERIMENTS}

In order to clarify these points, three experiments measuring blood flow and perfusion in the canine pancreas, both before and six hours after induction of pancreatitis, have been carried out.

In Experiment 1 six dogs between 15.5 and $30.4 \mathrm{~kg}$ (mean 23.7) were examined to assess blood flow and perfusion in different regions of the gland in which no vessels were ligated. In Experiment 2 seven dogs 
between 13.6 and $26.8 \mathrm{~kg}$ (mean 21.2) were used to evaluate flow and perfusion in the gland after accessory vessel ligation. In Experiment 3 six dogs between 14.7 and $38.0 \mathrm{~kg}$ (mean 23.6) were used to examine flow and perfusion in a preparation of the head of the gland alone, which allowed arteriovenous shunt flow to be assessed.

\section{OPERATIVE TECHNIQUE}

In all experiments food was withheld for 18 hours before operation. Anaesthesia was induced with thiopentone $(25 \mathrm{mg} / \mathrm{kg})$ and maintained with pentobarbitone $(30 \mathrm{mg} / \mathrm{kg})$. After endotracheal intubation, lung ventilation was achieved with a $2: 1$ mixture of nitrous oxide and oxygen using a respirator. Fluid was replaced with $0 \cdot 2 \%$ normal saline $/ 5 \%$ dextrose into a foreleg vein.

A cannula was inserted into the right femoral artery and connected to a transducer for recording arterial blood pressure. Through a left thoracotomy incision, the pericardium was opened and a precalibrated $20 \mathrm{~mm}$ diameter electromagnetic flow probe (Gould Statham) placed around the ascending aorta for monitoring cardiac output, and the chest closed.

The abdomen was opened through a midline incision. In order to introduce ${ }^{85} \mathrm{Kr}$ into the arterial supply of the pancreas it is necessary to be familiar with the blood supply: the head and varying degrees of the body of the gland and the uncinate process are supplied by the superior pancreaticoduodenal artery; part of the body and the tail of the gland are supplied by branches from the splenic artery and part of the uncinate process by the inferior pancreaticoduodenal artery. ${ }^{613}$

In Experiment 1 perfusion in the head, uncinate process, body and tail of the gland was examined. To inject ${ }^{85} \mathrm{Kr}$ into the superior pancreaticoduodenal artery a cannula was placed in the right gastroepiploic artery and introduced up to the bifurcation of the gastroduodenal artery. The position was checked by injecting Patent Blue dye (May and Baker Ltd) which, when correctly positioned at the origin of the superior pancreaticoduodenal artery, temporarily coloured the head and part of the body of the pancreas and the adjoining section of the duodenum blue. The cannula was then fixed in position. If the dye did not colour the uncinate process a cannula was placed in a branch of the inferior pancreaticoduodenal artery, distal to the branch supplying the uncinate process, and introduced down to the junction. The position was checked by injecting Patent Blue dye and the cannula was then fixed in position.

In Experiment 2 the accessory vessels, which included all branches from the splenic artery to the body and tail of the gland and also the inferior pancreaticoduodenal artery, were ligated leaving the superior pancreaticoduodenal artery and vein alone to supply and drain the gland. To ensure all the accessory vessels had been divided the body and tail were mobilised completely up to the neck of the gland and the uncinate process up to the head. A cannula was placed in the right gastroepiploic artery for injection of ${ }^{85} \mathrm{Kr}$ as previously described.

In Experiment 3 a preparation of the head of the pancreas alone was examined. In this preparation the uncinate process, body and tail of the gland were completely excised and the pancreaticoduodenal vascular connections divided. Therefore the head of the pancreas was completely isolated, being supplied and drained solely by the superior pancreaticoduodenal artery and vein. As before, a cannula was placed in the right gastroepiploic artery to allow injection of ${ }^{85} \mathrm{Kr}$. Isolation of the head of the gland was confirmed by injecting Patent Blue dye into this cannula, which stained the head of the pancreas alone when isolation was complete.

MEASUREMENT OF FLOW AND PERFUSION A precalibrated $2.5 \mathrm{~mm}$ diameter electromagnetic flow probe (Gould Statham) was placed around the gastroduodenal artery, constricting it slightly to ensure satisfactory contact of the electrodes. The electromagnetic measurements of cardiac output $(1 / \mathrm{min})$ and pancreatic blood flow $(\mathrm{ml} / \mathrm{min})$ were obtained using the SP2204 and SP2202 flowmeters respectively. These measurements, together with blood pressure, were continuously recorded on a chart recorder.

Once the operative procedures had been completed the experimental animals were left to stabilise for one hour. Temperature was maintained at $36-38^{\circ} \mathrm{C}$ by radiant heat lamps. Arterial blood gases were maintained at normal values and the base deficit controlled by intravenous injection of $8.4 \%$ sodium bicarbonate when necessary.

After the stabilisation period, perfusion was measured in the gland by injecting ${ }^{85} \mathrm{Kr}$ dissolved in normal saline into the arterial supply. The clearance in each area was recorded with a Geiger-Müller tube (Mini Instruments Ltd.) held just above the surface of the gland. A permanent record was made using a rate meter (Scaler) and chart recorder (Servoscribe IS recorder).

CALCULATION OF PANCREATIC PERFUSION

Pancreatic perfusion was calculated using the standard inert gas clearance equation:

$$
\text { Perfusion }=\frac{\lambda \cdot \log _{\mathrm{e}} 2 \cdot 60 \cdot 100}{\mathrm{~T}_{1 / 2}} \mathrm{ml} / \mathrm{min} / 100 \mathrm{~g}
$$

The value of $\lambda$, the partition coefficient of ${ }^{85} \mathrm{Kr}$ 
between the pancreas and blood, has been previously reported as $0 \cdot 90 .{ }^{15} T_{1 / 2}$ is the time (sec) for radioactivity to decay to one half of its original value. This value was determined by replotting the chart data on logarithmic-linear graph paper. Curves were analysed as previously reported. ${ }^{15}$

In Experiment 1 perfusion was first measured in the head of the gland by injecting ${ }^{85} \mathrm{Kr}$ into the cannula in the right gastroepiploic artery. Perfusion was then measured in the uncinate process by injecting ${ }^{85} \mathrm{Kr}$ into the cannula in the right gastroepiploic artery if the uncinate process was perfused by the superior pancreaticoduodenal artery or, if not, into the cannula in the branch of the inferior pancreaticoduodenal artery. Perfusion was next measured in the body of the gland by injecting ${ }^{85} \mathrm{Kr}$ into the cannula in the right gastroepiploic artery. The isotope did not reach the tail of the pancreas by injecting into the cannula in the right gastroepiploic artery in any of the dogs; perfusion in this area was measured by injecting ${ }^{85} \mathrm{Kr}$ into the splenic artery.

In Experiment 2 perfusion was measured in each of the four areas in turn. In Experiment 3 three measurements of perfusion were taken over the head of the gland. In both these experiments ${ }^{85} \mathrm{Kr}$ was injected into the cannula in the right gastroepiploic artery.

\section{INDUCTION OF ACUTE PANCREATITIS}

Acute haemorrhagic pancreatitis was then induced by injecting $10 \mathrm{ml}$ of autologous bile into the pancreatic duct in Experiment 1 and Experiment 2 and $5 \mathrm{ml}$ bile in Experiment $3 .^{4}$ The animal was maintained for a further 5.5 hours with regular blood gas analyses being done and the base deficit corrected. After this time measurements of ${ }^{85} \mathrm{Kr}$ clearance in each experiment were repeated as before the induction of pancreatitis. An approximate time of one hour was necessary to complete the measurements; therefore the mean duration of disease when measurements were taken was about six hours. The animals were then killed. In all three experiments biopsies of the pancreas were taken for histological examination. In addition, in Experiment 3 the head of the gland was removed and weighed.

DATA PRESENTATION AND ANALYSIS

Data presented include mean blood pressure ( $\mathrm{mmHg})$, cardiac output $(1 / \mathrm{min})$ and the electromagnetic flow measurements of pancreatic flow $(\mathrm{ml} / \mathrm{min})$ in the normal pancreas and in acute pancreatitis. These values in each dog, both before and during disease, were expressed as the mean of the four values taken at each group of clearance measurements in Experiment 1 - that is, head, uncinate process, body and tail, or the mean of three measurements in Experiment 2 - that is, head, uncinate process and body, and also the mean of three measurements in Experiment 3 (all head of the gland). In addition, the percentage of the cardiac output distributed to the pancreas in each dog was calculated by dividing the mean pancreatic flow ( $\mathrm{ml} / \mathrm{min}$ ) by the mean cardiac output (expressed in $\mathrm{ml} / \mathrm{min}$ ) and multiplying by 100 . In each experiment the above data are presented as the mean \pm standard error of the mean in all the dogs; perfusion is also presented as the mean \pm standard error of the mean in each area of the gland in all the dogs. In Experiment 3 as the superior pancreaticoduodenal artery supplied the head of the gland alone it was possible to express the electromagnetic flow measurements of flow in $\mathrm{ml} / \mathrm{min} / 100 \mathrm{~g}$ by dividing the flow $(\mathrm{ml} / \mathrm{min})$ by the weight $(\mathrm{g})$ and multiplying by 100 . The mean value of these three readings in each dog were then compared with the ${ }^{85} \mathrm{Kr}$ clearance measurements. Student's paired $t$ test was used to compare the data within each experimental group.

\section{Results}

All data are shown in the Table.

\section{EXPERIMENT 1}

Two electromagnetic flow measurements of pancreatic flow $(\mathrm{ml} / \mathrm{min})$ were unstable and in these two dogs the mean pancreatic flow was calculated from the three remaining readings.

Mean blood pressure $(\mathrm{mmHg})$ fell from $138 \cdot 2 \pm 6 \cdot 4$ to $110.2 \pm 11.1(\mathrm{p}<0.05)$ and cardiac output $(1 / \mathrm{min})$ fell from $1.91 \pm 0.25$ to $1.39 \pm 0.13(\mathrm{p}<0.05)$. Pancreatic flow $(\mathrm{ml} / \mathrm{min})$ fell from $49.3 \pm 11.3$ to $30.1 \pm 7.5(p<0.05)$, but the percentage of the cardiac output distributed to the pancreas was similar in the normal gland and in acute pancreatitis $(2.48 \pm 0.41,2.06 \pm 0.37$ respectively).

In the normal pancreas there was no difference in perfusion $(\mathrm{ml} / \mathrm{min} / 100 \mathrm{~g})$ comparing the head $(108 \cdot 5 \pm 12 \cdot 7)$ with the uncinate process $(112 \cdot 6 \pm 8 \cdot 5)$, body $(105 \cdot 7 \pm 13 \cdot 2)$ and tail $(119 \cdot 7 \pm 17 \cdot 7)$. In pancreatitis perfusion in the head $(94.6 \pm 15.8)$ was also similar to that in the uncinate process $(76 \cdot 0 \pm 12 \cdot 6)$, body $(116 \cdot 2 \pm 24 \cdot 0)$ and tail $(92 \cdot 6 \pm 16 \cdot 3)$. Comparing perfusion in the corresponding regions in the normal gland and in pancreatitis there were no differences.

\section{EXPERIMENT 2}

No data were rejected in this experiment.

Mean blood pressure $(\mathrm{mmHg})$ was similar in the normal gland (113.1 $\pm 6 \cdot 7)$ and in acute pancreatitis $(111 \cdot 4 \pm 5 \cdot 4)$. Cardiac output $(1 / \mathrm{min})$ fell from $1.68 \pm 0.11$ in the normal gland to $0.86 \pm 0.11$ in acute 
Table Blood flow measurements in three experiments

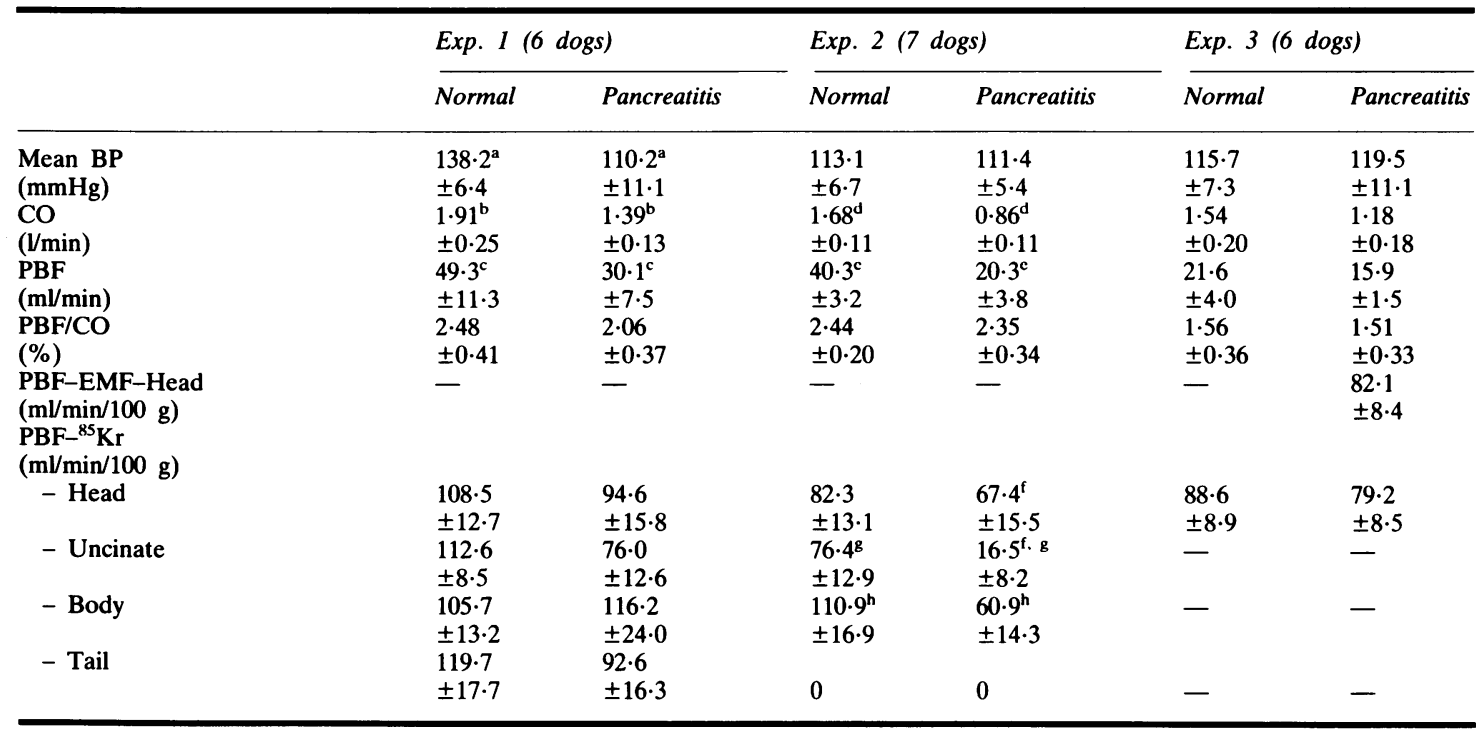

Experiment 1: no vessels ligated;

Experiment 2: accessory vessels ligated;

Experiment 3: head alone supplied by superior pancreaticoduodenal artery.

Data expressed as mean \pm standard error of the mean.

$\mathrm{BP}=$ blood pressure, $\mathrm{CO}=$ cardiac output, $\mathrm{PBF}=$ pancreatic blood flow, $\mathrm{PBF} / \mathrm{CO}(\%)=$ percentage of cardiac output distributed to the pancreas, EMF=electromagnetic flow, ${ }^{85} \mathrm{Kr}=\mathrm{Krypton}-85$ clearance.

Paired letters represent significant differences between the two groups $(a, b, c, f, h: p<0 \cdot 05 ; d, e: p<0.005 ; g: p<0.01)$.

pancreatitis $(\mathrm{p}<0 \cdot 005)$. Pancreatic flow $(\mathrm{ml} / \mathrm{min})$ also fell from $40 \cdot 3 \pm 3 \cdot 2$ to $20 \cdot 3 \pm 3 \cdot 8(\mathrm{p}<0 \cdot 005)$. The percentage of the cardiac output distributed to the pancreas did not change $(2 \cdot 44 \pm 0 \cdot 20$ and $2 \cdot 35 \pm 0.34$ respectively).

After ligation of accessory vessels, the tail always became macroscopically ischaemic. Consequently no perfusion measurements were made in the tail. Varying amounts of the body became ischaemic and perfusion was measured in the proximal, viable part. Perfusion $(\mathrm{ml} / \mathrm{min} / 100 \mathrm{~g})$ in the head $(82 \cdot 3 \pm 13 \cdot 1)$ was similar to that in the uncinate process $(76 \cdot 4 \pm 12 \cdot 9)$ and in the body $(110 \cdot 9 \pm 16.9)$. In acute pancreatitis perfusion in the head $(67 \cdot 4 \pm 15.5)$ was similar to that in the body $(60.9 \pm 14.3)$ but perfusion in the uncinate process was lower $(16.5 \pm 8 \cdot 2)(\mathrm{p}<0.05)$. Comparing perfusion in the corresponding regions before and during disease there was no change in the head but perfusion fell in the uncinate process $(p<0.01)$ and in the body $(p<0.05)$.

\section{EXPERIMENT 3}

One electromagnetic flow measurement of pancreatic flow $\left(\mathrm{ml} / \mathrm{min}\right.$ ) was unstable and one ${ }^{85} \mathrm{Kr}$ measure- ment of perfusion $(\mathrm{ml} / \mathrm{min} / 100 \mathrm{~g})$ was difficult to analyse. Therefore these two measurements were rejected leaving two values in each of the groups from which the mean was calculated.

Mean blood pressure $(\mathrm{mmHg})$ was similar in the normal gland and in acute pancreatitis $(115 \cdot 7 \pm 7 \cdot 3$ and $119.5 \pm 11.1$ respectively). Similarly, cardiac output $(1 / \mathrm{min})(1.54 \pm 0.20$ and $1.18 \pm 0.18 \mathrm{respec}-$ tively), pancreatic flow $(\mathrm{ml} / \mathrm{min})(21.6 \pm 4.0$ and $15.9 \pm 1.5$ respectively), and the percentage of the cardiac output distributed to the gland $(1 \cdot 56 \pm 0.36$ and $1.51 \pm 0.33$ respectively) did not change.

Perfusion measurements $(\mathrm{ml} / \mathrm{min} / 100 \mathrm{~g})$ in the head were similar in the normal gland $(88.6 \pm 8.9)$ and in acute pancreatitis $(79 \cdot 2 \pm 8 \cdot 5)$. Comparing the electromagnetic flow measurements of perfusion $(82 \cdot 1 \pm 8.4 \mathrm{ml} / \mathrm{min} / 100 \mathrm{~g})$ with the ${ }^{85} \mathrm{Kr}$ clearance measurements in pancreatitis there was also no difference.

The weight of the head of the gland varied from 15.5 to $24 \cdot 7 \mathrm{~g}$ (mean 19.7).

Histological examination from the biopsies in all the experiments confirmed acute haemorrhagic pancreatitis. 


\section{Discussion}

Experiment 1 shows that if the vasculature of the pancreas is left intact, perfusion in all regions is similar in the normal gland and in acute pancreatitis and there is no difference between the regions before or during disease.

Experiment 2 examines the pancreas in which accessory vessels were ligated. The model was first described by Eichelter and Schenk to measure blood flow in the normal canine pancreas. ${ }^{16}$ Since that time the preparation has been used by several investigators to examine changes in the percentage of the cardiac output being distributed to the gland in disease. ${ }^{4-11}$ In the present study, after ligation of the accessory vessels, perfusion in the head, uncinate process and proximal part of the body of the normal gland did not change, but the tail and varying amounts of the body became ischaemic. In acute pancreatitis, perfusion in the uncinate process $(16.5 \pm 8.2 \mathrm{ml} / \mathrm{min} / 100 \mathrm{~g})$ was significantly lower than in the head of the gland $(67 \cdot 4 \pm 15 \cdot 5)$. Comparing perfusion in the uncinate process before and during disease, perfusion fell from $76.4 \pm 12.9 \mathrm{ml} / \mathrm{min} / 100 \mathrm{~g}$ to $16.5 \pm 8.2 \mathrm{ml} / \mathrm{min} / 100 \mathrm{~g}$, and in the body from $110 \cdot 9 \pm 16 \cdot 9$ to $60 \cdot 9 \pm 14 \cdot 3$, falls of $78 \cdot 4 \%$ and $45 \cdot 1 \%$ respectively. Therefore, in this model, although perfusion was maintained in the head of the gland, it was not in the uncinate process or body, which suggests that the diseased gland did not have the capacity to maintain flow in the areas which were most likely to have been affected by the accessory vessel ligation. In Experiment 1, however, in which no vessels were ligated, perfusion was not affected by disease. These features suggest that accessory vessel ligation has compromised blood flow to the pancreas in certain areas in both the normal gland and to a greater degree in acute pancreatitis. Consequently this particular model is considered to be unsuitable for the study of arterial flow in the canine pancreas.

In Experiment 3, in which the head of the gland alone was examined, there was no change in perfusion after induction of disease. In addition, the electromagnetic flow measurements of perfusion $(82 \cdot 1 \pm 8 \cdot 4 \mathrm{ml} / \mathrm{min} / 100 \mathrm{~g})$ were remarkably similar to the ${ }^{85} \mathrm{Kr}$ clearance perfusion measurements (79.2 $\pm 8 \cdot 5)$. The electromagnetic flow measurements could not be standardised with the ${ }^{85} \mathrm{Kr}$ clearance measurements in Experiment 1 as it was not possible to assess what weight of the gland was being perfused by this artery alone. In Experiment 2, although it would have been possible to excise the macroscopically ischaemic areas, it is unclear what effect the differences in regional perfusion would have had on the electromagnetic flow measurement.
In addition, in Experiments 1 and 2 the pancreaticoduodenal vessels were not ligated; consequently part of the measured flow to the pancreas supplied the duodenum - it has previously been shown that this leads to a $35 \cdot 5 \%$ overestimate of pancreatic flow. ${ }^{15}$

Of the three models examined in the experiments, the preparation of the head alone appears to be the model of choice for the techniques used to measure flow and perfusion. Removal of the uncinate process, body and tail of the gland has two advantages: (i) areas of suspect perfusion are eliminated, and (ii) the electromagnetic flow measurements can be standardised with the ${ }^{85} \mathrm{Kr}$ clearance measurements and confirm flow changes. Unfortunately as the weight of the gland is not known before inducing disease it is not possible to assess the electromagnetic flow measurements in $\mathrm{ml} / \mathrm{min} / 100 \mathrm{~g}$ in the normal state.

As the electromagnetic flow technique measures arterial flow to the gland and ${ }^{85} \mathrm{Kr}$ clearance measures perfusion, if the electromagnetic flow measurements were higher than the ${ }^{85} \mathrm{Kr}$ clearance measurements one could postulate that the difference was due to arteriovenous shunt flow. In this model there was no difference, refuting this possibility in the head of the gland. Papp et al ${ }^{14}$ studied the changes in the vasculature in canine bile induced acute haemorrhagic pancreatitis 24 hours after induction of disease. After death the superior pancreaticoduodenal artery or vein was injected with polyvinyl chloride or an Indian ink/gelatine mixture and examined histologically - they noted an increase in the number of arteriovenous shunts. Wulff and Sjöström ${ }^{12}$ assessed arteriovenous shunt flow in severe disease by examining the distribution of radiolabelled microspheres after injection into the arterial supply. They found no evidence of arteriovenous shunt flow in haemorrhagic pancreatitis. Knol $e t$ at ${ }^{6}$ assessed shunt flow using a similar technique. The shunt flow was fairly constant during their experiment at 1-2 $\mathrm{ml} / \mathrm{min}$ and was not affected by pancreatitis. The results of Experiment 3 are therefore in agreement with the latter two reports.

Many investigators have found that the percentage of the cardiac output distributed to the gland in acute haemorrhagic pancreatitis falls. ${ }^{124}$ 8-11 The three experiments in the present study, however, have shown no change. Methods used to measure blood flow in these experiments have included isotope fractionation, ${ }^{12}$ distribution of radiolabelled microspheres ${ }^{5}$ and the electromagnetic flow technique using the accessory vessel ligated model. ${ }^{4}$ 8-11 In contrast with these results Wulff and Sjöström ${ }^{12}$ found a relative increase in the percentage using radiolabelled microspheres, and Knol et al found no change using the electromagnetic flow technique. 
In Wulff and Sjöström's experiment ${ }^{12}$ heparin was used to keep the catheters patent and this may have affected blood flow in the gland. ${ }^{2}$

Wulff and Sjöström ${ }^{12}$ recorded increasing metabolic acidosis during the course of experimental disease - in none of the studies described previously was this metabolic abnormality corrected. In this study arterial blood gases were closely monitored and any abnormality in acid base balance corrected. It is therefore possible that in previously reported studies this abnormality led to increased susceptibility of perfusion in disease, leading to a relative reduction in flow.

In conclusion, in acute haemorrhagic pancreatitis in the dog, perfusion in different regions of the gland does not change if all vessels are intact. If the accessory vessels are divided, however, leaving the superior pancreaticoduodenal artery alone to supply the gland, the tail and part of the body become ischaemic and, in acute pancreatitis, perfusion falls in the uncinate process and body. The percentage of the cardiac output distributed to the pancreas does not change during the disease. Previous investigations suggesting that the percentage does fall have been carried out in dogs in which acid base imbalance has not been corrected. It is possible that the difference is due to deranged acid base balance. There is no evidence to suggest that there is arteriovenous shunt flow in disease.

We wish to thank Marhokh Nohadani for preparing the slides and Brigitte Studley for typing the manuscript.

\section{References}

1 Papp M, Makara GB, Hajtman B, Csáki L. A quantitative study of pancreatic blood flow in experimental pancreatitis. Gastroenterology 1966; 51: 524-8.

2 Goodhead B. Vascular factors in the pathogenesis of acute haemorrhagic pancreatitis. Ann R Coll Surg Engl 1969; 45: 80-97.
3 Pissiotis CA, Condon RE, Nyhus LM. Effect of vasopressin on pancreatic blood flow in acute hemorrhagic pancreatitis. Am J Surg 1972; 123: 203-8.

4 Donaldson LA, Williams RW, Schenk WG, Jr. Experimental pancreatitis: effect of plasma and dextran on pancreatic blood flow. Surgery 1978; 84: 313-9.

5 Becker H, Vinten-Johansen J, Buckberg GD, Bugyi HI. Correlation of pancreatic blood flow and highenergy phosphates during experimental pancreatitis. Eur Surg Res 1982; 14: 203-10.

6 Knol JA, Edgcomb LP, Inman MS, Eckhauser FE. Low molecular weight dextran in experimental pancreatitis: effects on pancreatic microcirculation. J Surg Res 1983; 35: 73-82.

7 Hermreck AS, Smith EI, Thal AP. Acute edematous pancreatitis: metabolic and hemodynamic studies. Surg Forum 1968; 19: 368-70.

8 Studley JGN, Schenk WG Jr. Pathophysiology of acute pancreatitis. Evaluation of the effects and mode of action of steroids in experimental pancreatitis in dogs. Am J Surg 1982; 143: 761-4.

9 Studley JGN, Lee JB, Schenk WG, Jr. Pathophysiology of acute pancreatitis: evaluation of the effects and mode of action of indomethacin in experimental pancreatitis in dogs. J Surg Res 1982; 32: 363-8.

10 Wells AD, Schenk WG Jr. Beneficial effect of ethamsylate on the relative blood flow in the pancreas in acute canine necrotizing pancreatitis. Surg Gynecol Obstet 1982; 155: 673-8.

11 Wells AD, Imahori SC, Schenk WG Jr. Does edematous pancreatitis exist in biliary-related pancreatitis? Arch Surg 1982; 118: 1277-82.

12 Wulff K, Sjöström B. Influence of acute pancreatitis on central hemodynamic, regional blood flow distribution and arteriovenous shunting in the dog. Eur Surg Res 1974; 6: 354-63.

13 Hermon-Taylor J. A technique for perfusion of the isolated canine pancreas. Gastroenterology 1968; 55: 488-501.

14 Papp M, Ungvari Gy, Németh PE, Munkácsi I, Zubek L. The effect of bile-induced pancreatitis on the intrapancreatic vascular pattern in dogs. Scand $J$ Gastroenterol 1969; 4: 681-9.

15 Studley JGN, Mathie RT, Blumgart LH. An evaluation of blood flow and perfusion in the canine pancreas. Acta Chir Scand 1985; 151: 551-6.

16 Eichelter P, Schenk WG Jr. Hemodynamics of pancreatic secretion. Arch Surg 1966; 93: 200-7. 